\title{
Pervaporation Process with PDMS/PVDF Hollow Fiber Composite Membrane to Recycle Phenol from Coal Chemical Wastewater
}

\author{
Yao Jie ${ }^{1,2,}$, Zhang Dandan ${ }^{1}$, Yang Shuren ${ }^{1}$, You Hong ${ }^{1}$, Du Ziwei ${ }^{1}$, Li Biaoming ${ }^{3}$, \\ Yang Zhou ${ }^{2}$, Wang Zhongwei ${ }^{2}$, Sjack van Agtmaal ${ }^{4}$, Feng Chunhui ${ }^{4}$ and Han Bangjun ${ }^{5}$ \\ ${ }^{1}$ School of Municipal and Environmental Engineering, Harbin Institute of Technology, Harbin 150090, P. R. \\ China \\ ${ }^{2}$ National Engineering Centre of Urban Water Resources, 202 Hehai Road, Harbin 150090, P.R. China \\ ${ }^{3}$ Municipal Planning and Designing Institute of Changchun, No.8888, Ziyou Road Changchun 130000, P.R. \\ China \\ ${ }^{4}$ Evides Industriewater B.V. Schaardijk 150, 3063 NH Rotterdam, the Netherlands \\ ${ }^{5}$ School of Civil Engineering, Heilongjiang University, Xuefu Road, Harbin150090, P.R. China
}

\begin{abstract}
To treat coal gasification wastewater containing phenol, polydimethylsiloxane (PDMS)/polyvinylidene fluoride (PVDF) hollow fiber composite membrane was made by dynamic negative pressure coating method, using PVDF hollow fiber membrane as base membrane, PDMS as modifying membrane material, to improve pervaporation performance of PDMS by the cross-linking modification. The influence of cross-linking agent, PDMS concentration, coating time on pervaporation performance of the composite membrane was investigated. Actual coal chemical wastewater with phenol concentration $1600-1800 \mathrm{mg} / \mathrm{L}$, COD $13000-15000 \mathrm{mg} / \mathrm{L}$ was treated by the obtained PDMS/PVDF composite membrane, and at temperature $70^{\circ} \mathrm{C}$, the flow rate of $10 \mathrm{~L} / \mathrm{h}$, pressure under membrane $3 \mathrm{KPa}$, phenol flux 16.81 $\mathrm{g} /\left(\mathrm{m}^{2} \cdot \mathrm{h}\right)$, separation factor reaches 8.103 .
\end{abstract}

Keywords: Hollow fiber composite membrane, dynamic negative pressure coating, cross-linking modification, pervaporation, coal chemical wastewater.

\section{INTRODUCTION}

Coal chemical industries result in a large amount of high concentration organic wastewater, mainly phenolic compounds, alkane, aromatic hydrocarbons, heterocyclic, ammonia nitrogen and cyanide, which are hard to be treated by traditional biological treatment. At the same time, phenolic is an important basic material in organic synthesis [1], so if large amount of phenolic substances be recovered or recycled, it would produce huge economic and environmental benefit.

Pervaporation is an industrial process with low energy consumption, being environmental friendly and promising, especially suitable for separating azeotrope, the isomers with same boiling point and thermosensitive substance [2]. In comparison with the plate-and-frame module, the hollow fiber membrane [3, 4] has the advantages of high-packing density, selfcontained mechanical support, self-contained vacuum channel and economical superiority. The PDMS with side chain modification [5] has better pervaporation

*Address correspondence to this author at the School of Municipal and Environmental Engineering, Harbin Institute of Technology, Harbin 150090, P. R. China; Tel: 0086-13904501245; Fax: 0086-451-86283082;

E-mail: yaojiejie@hotmail.com performance and so PDMS/PVDF hollow fiber composite membrane was made by dynamic negative pressure coating method, and pervaporation performance of PDMS was improved by the crosslinking modification. The influence of cross-linking agent, PDMS concentration, coating time on the pervaporation performance of the composite membrane was investigated in this paper.

\section{EXPERIMENTAL}

\subsection{Materials and Reagents}

PVDF hollow fiber membrane module (pore size $0.16 \mu \mathrm{m}$, hollow fiber inner diameter $0.8 \mathrm{~mm}$, external diameter $1.16 \mathrm{~mm}$, membrane area $553 \mathrm{~cm}^{2}$, (Institute of Biological \& Chemical Engineering, Tianjin Polytechnic University); polydimethylsiloxane (PDMS) with molecular weight 6000 (Heowns Biochem Technologies Co. Ltd.), tetraethoxysilane (Heowns Biochem Technologies Co. Ltd.), (3 - cyanide propyl) triethoxy silane (Heowns Biochem Technologies Co.Ltd.), dibutyltin dilaurate (Heowns Biochem Technologies Co. Ltd.), n-hexane, analytically pure (National Medicine Group Chemical Reagent Co. Ltd.) were used. 


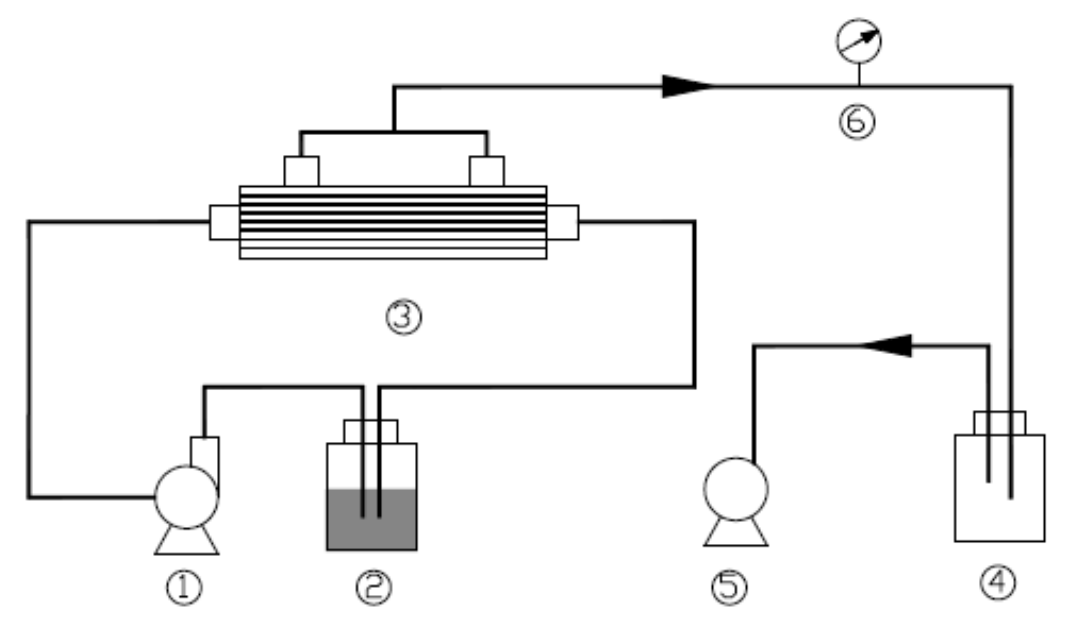

Figure 1: Coating process diagram. 1. Peristaltic pump; 2. Material liquid tank; 3. Hollow fiber membrane module; 4. Buffer bottle; 5 . Vacuum pump; 6 . Vacuum gauge.

\subsection{Preparation of Composite Membrane}

PDMS casting solution was prepared by dissolving PDMS, cross-linking agent and catalyst (dibutyltin dilaurate) with a certain mass ratio in $\mathrm{n}$-hexane with continuous adding of $n$-hexane, stirring, centrifugating, and deaerating. PVDF membrane was activated by pumping the heated $\mathrm{NaOH}$ solution $\left(65^{\circ} \mathrm{C}\right.$, concentration $2 \mathrm{~mol} / \mathrm{L}$ ) into hollow fiber membrane for $15 \mathrm{~min}$, then rinsing the membrane with deionized water till the effluent water $\mathrm{pH}$ being neutral. Composite membranes were prepared by a dynamic negative pressure coating method, as shown in Figure $\mathbf{1}$. Peristaltic pump was used to pump the PDMS casting solution into hollow fiber module, the flow direction of casting solution changed every $10 \mathrm{~min}$. Vacuum pump was used to produce certain negative pressure $(0.06$ $\mathrm{MPa}$ ) in the hollow fiber membrane shell to form a composite layer after a certain time and cross-link last for $48 \mathrm{~h}$ in $30^{\circ} \mathrm{C}$ till the membrane being dry.

\subsection{Pervaporation Performance Testing Process}

The pervaporation performance of membrane was tested in pervaporation setup, shown in Figure 2, in which heated wastewater, from Qitaihe Baotailong Coal Chemical Co. Ltd, was pumped into the membrane reaction tank, the treated water recycled back into waste water storage bottle. In membrane reaction tank, organic pollution in wastewater pervaporated into gas phase through membrane because of the negative pressure made by vacuum pump, then cooled and collected, the phenol concentration being determined by 4-Aminoantipyrine spectrophotometry. The characteristics of coal chemical wastewater were shown in Table 1. The wastewater mainly contain phenol, cresol, benzodiazepines, heterocyclic compounds and so on. 1L wastewater was used for test, and experimental operating conditions were as water temperature at $70^{\circ} \mathrm{C}$, circulation flow rate fixed at $10 \mathrm{~L} / \mathrm{h}$, pressure under membrane $3 \mathrm{KPa}$.

The pervaporation process evaluation index is the permeation flux and separation factor as formula (1-1) and (1-2):

$J=\frac{W}{A \cdot \Delta t}$

In which: J-permeation flux, $\mathrm{g} /\left(\mathrm{m}^{2} \cdot \mathrm{h}\right) ; \quad W-$ permeation mass, g; $A$-membrane area, $\mathrm{m}^{2} ; \Lambda t-$ operating time, $\mathrm{h}$.

$$
\alpha=\frac{Y_{A} / Y_{B}}{X_{A} / X_{B}}
$$

Table 1: Characteristics of Coal Chemical Wastewater

\begin{tabular}{|c|c|c|c|}
\hline Items & Value & Items & Value \\
\hline \hline $\mathrm{COD}$ & $13000-15000 \mathrm{mg} / \mathrm{L}$ & $\mathrm{SS}$ & $580-650 \mathrm{mg} / \mathrm{L}$ \\
\hline $\mathrm{pH}$ & $7.5-8.1$ & Color & Brown yellow \\
\hline Phenol concentration & $1600-1800 \mathrm{mg} / \mathrm{L}$ & Temperature & $70-80^{\circ} \mathrm{C}$ \\
\hline
\end{tabular}


In which: $\alpha$-separation factor; $Y_{A}$-mass fraction of $\mathrm{A}$ in permeation(\%); $Y_{R}$-mass fraction of $\mathrm{B}$ in permeation (\%); $X_{A}$-mass fraction of $A$ in feed (\%); $X_{B}$ -mass fraction of $B$ in feed (\%).

\section{RESULTS AND DISCUSSION}

\subsection{Characterization of Coating Effect}

The characterization of coating effect of membrane inner face was tested by contact angle test, scanning electron microscope (SEM), energy dispersive X-ray spectroscopy (EDS), as shown in Figure $\mathbf{3}$ for original PVDF membrane, activated PVDF membrane and composite membrane.
The contact angle between membrane and water was significant increased from original PVDF membrane $\left(78.784^{\circ}\right)$ to coated composite membrane $\left(91.61^{\circ}\right)$, so the coated hollow fiber membrane was more hydrophobic which means less water permeation and higher separation factor. Observation of SEM and EDS testing would illustrate that the original PVDF membrane had a large number of micropores on inner surface; the micropores became larger after activated, while the material composition was still polyvinylidene fluoride; which verified that polydimethylsiloxane was successfully coated on the activated membrane inner face, filling pores on the inner surface and formed the perfect dense endodermis. The SEM of original PVDF
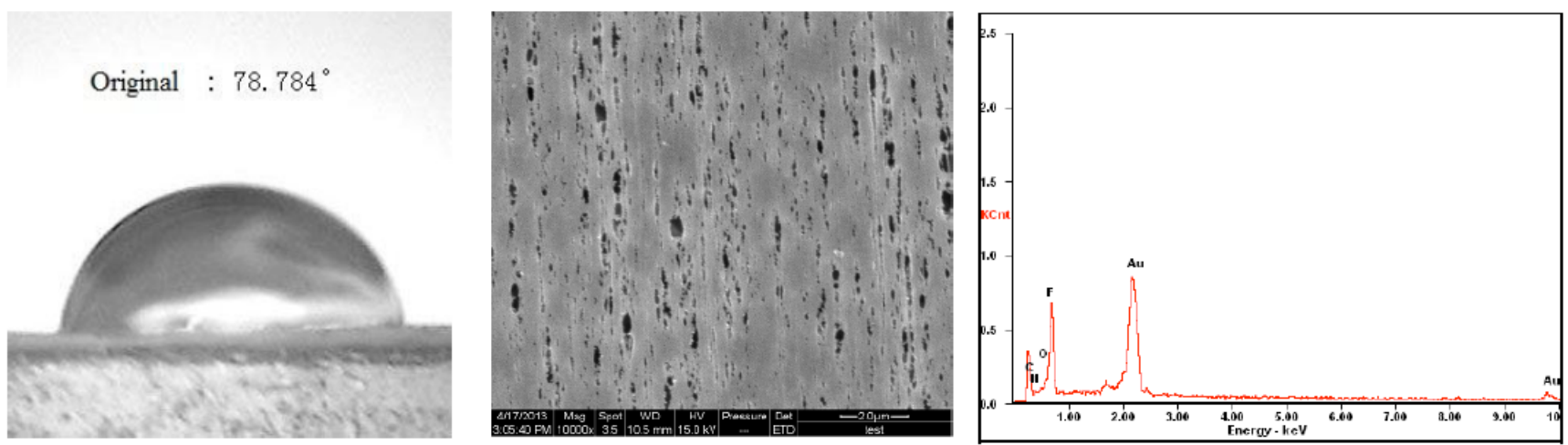

a) Original membrane contact angle

b) Original membrane SEM $\times 10000$

c) Original membrane EDS
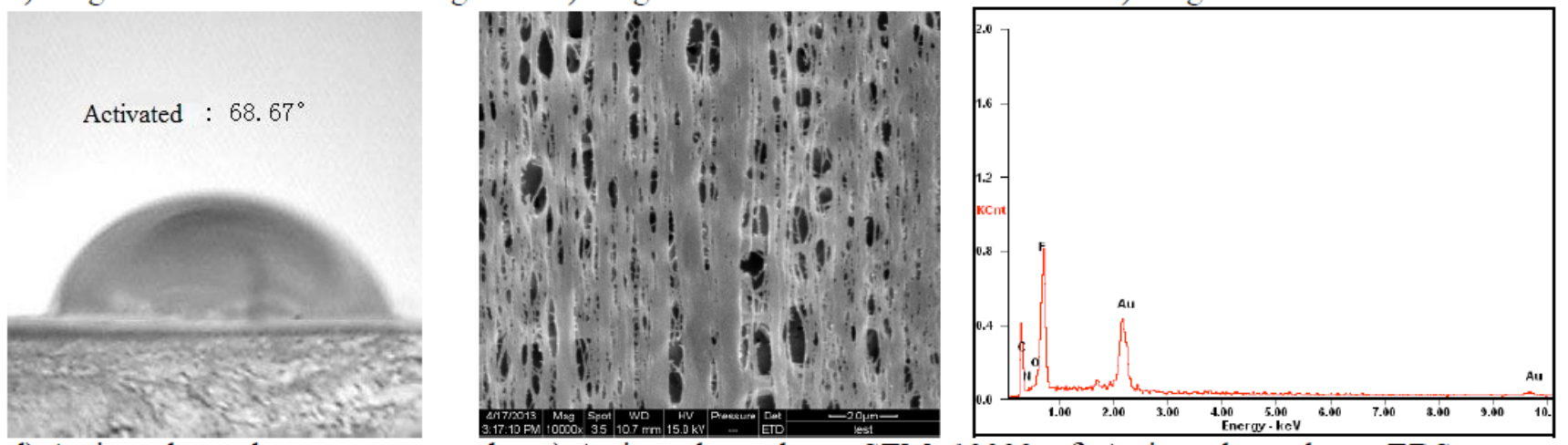

d) Activated membrane contact angle e) Activated membrane SEM $\times 10000$ f) Activated membrane EDS

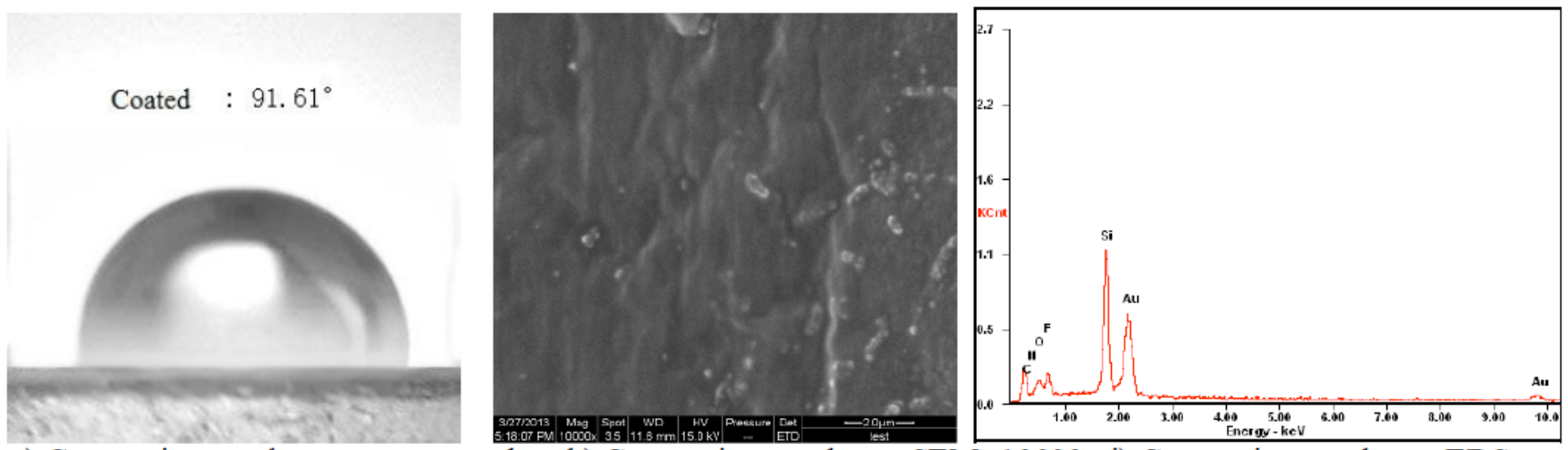

g) Composite membrane contact angle $\mathrm{h}$ ) Composite membrane SEM $\times 10000$ i) Composite membrane EDS

Figure 3: Membrane inner surface characterization. 

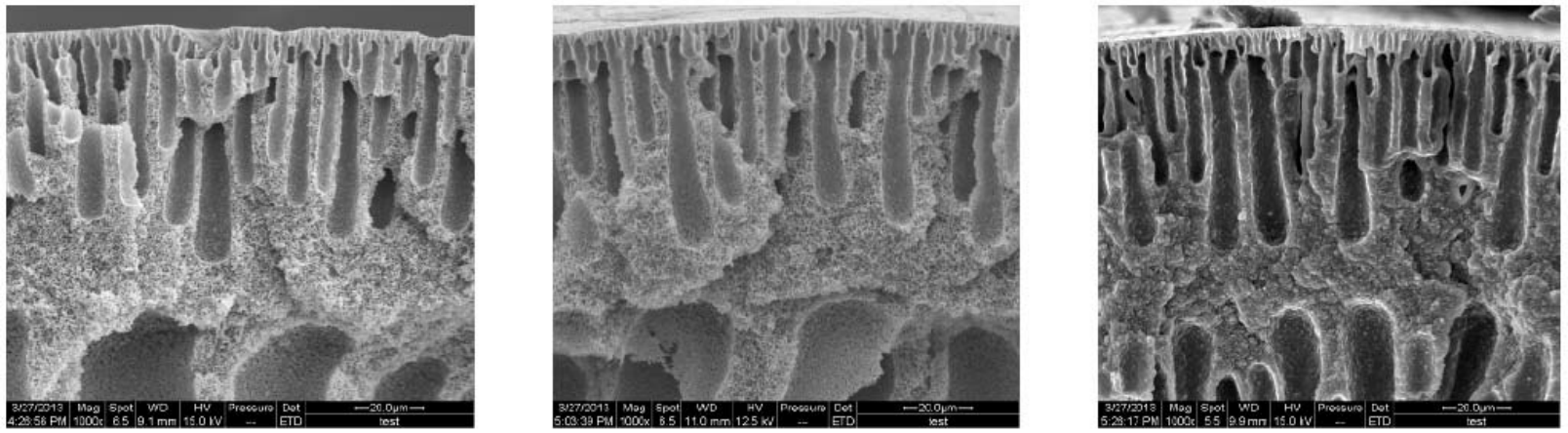

a) Original membrane $\mathrm{SEM} \times 1000$

b) Activated membrane SEM $\times 1000$

c) Composite membrane $\mathrm{SEM} \times 1000$
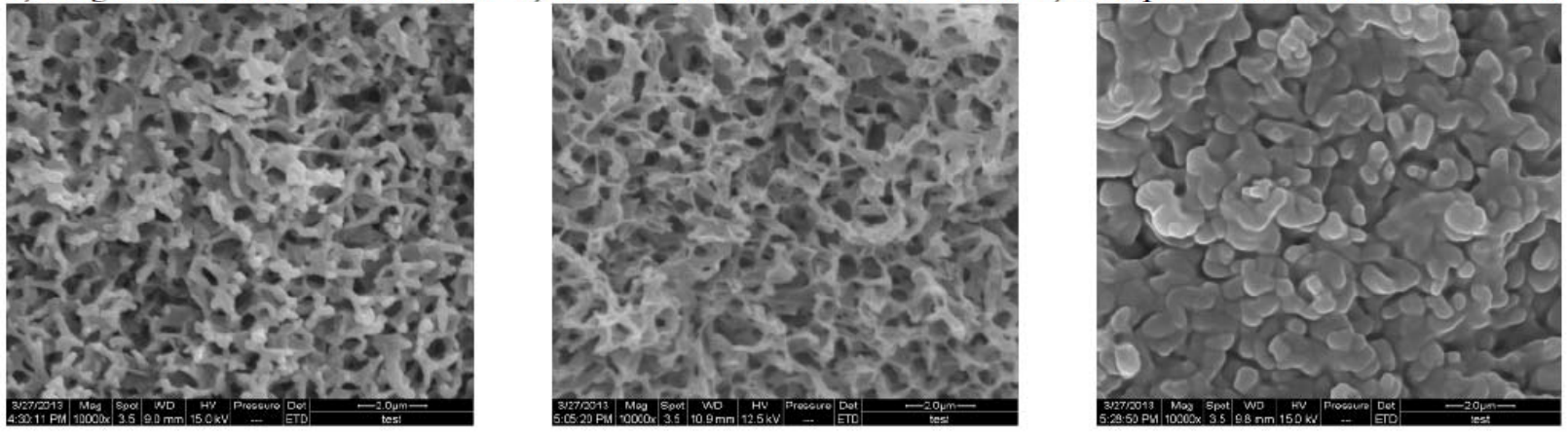

d) Original membrane SEM $\times 10000$ e) Activated membrane SEM $\times 10000$ f)Composite membrane SEM $\times 10000$

Figure 4: SEM pictures of hollow fiber membrane cross section.

membrane, activated PVDF membrane and composite membrane were shown in Figure 4.

The morphology change of original PVDF membrane, activated PVDF membrane, coated composite membrane could be easily observed by the cross section SEM pattern. The original PVDF membrane has highly developed porosity and smooth fracture surface and the roughness was significantly increased after activation and fracture surface show a jagged edges. The highly developed pores were filled and the jagged edges were coated by PDMS membrane material, which prove that PDMS membrane materials had been combined with PVDF internal structure through pores and formed a PDMS/PVDF composite structure.

Synthesis and pervaporation test illustrate that PDMS/PVDF composite membrane made by dynamic negative pressure coating method was perfect, solid and tight, PDMS dense endodermis being formed on the inner surface.

\subsection{Effect of Cross-Linking Modification on PDMS Composite Membrane Pervaporation Performance}

(3-cyanide propyl) triethoxy silane was used as cross-linking agent to introduce $-\mathrm{CN}$ into PDMS material and in order to guarantee same degree of cross-linking, formula and preparation conditions of two kinds of membrane were given in Table 2, including pervaporation performance of membranes. Two membranes were tested by infrared absorption spectrum for confirming the introduction of $-\mathrm{CN}$, and the membrane infrared image was shown in Figure $\mathbf{5}$.

The infrared spectrograms show $2963 \mathrm{~cm}^{-1}$ peak (C-H stretching vibration 3000-2843 $\mathrm{cm}^{-1}$ ), $1391 \mathrm{~cm}$

Table 2: PDMS Composite Membrane Preparation Conditions \& Pervaporation Performance

\begin{tabular}{|c|c|c|c|c|c|c|}
\hline Membrane & Mass ratio & $\begin{array}{c}\text { PDMS } \\
\text { concentration }\end{array}$ & $\begin{array}{c}\text { Coating } \\
\text { time } \\
\text { (min) }\end{array}$ & $\begin{array}{l}\text { Phenol } \\
\text { flux } \\
g /\left(\mathrm{m}^{2} \cdot h\right)\end{array}$ & $\begin{array}{l}\text { Water flux } \\
\mathrm{kg} /\left(\mathrm{m}^{2} \cdot \mathrm{h}\right)\end{array}$ & $\begin{array}{l}\text { Separate } \\
\text { factor }\end{array}$ \\
\hline $\begin{array}{l}\text { Original } \\
\text { PDMS }\end{array}$ & PDMS: tetraethoxysilane:DBTL=20:2:1 & $20 w t \%$ & 20 & 13.74 & 2.321 & 4.496 \\
\hline $\begin{array}{l}\text { Modified } \\
\text { PDMS }\end{array}$ & $\begin{array}{c}\text { PDMS: (3-cyanide propyl) triethoxy } \\
\text { silane:DBTL=20:3:1 }\end{array}$ & $20 w t \%$ & 20 & 17.52 & 2.737 & 5.793 \\
\hline
\end{tabular}




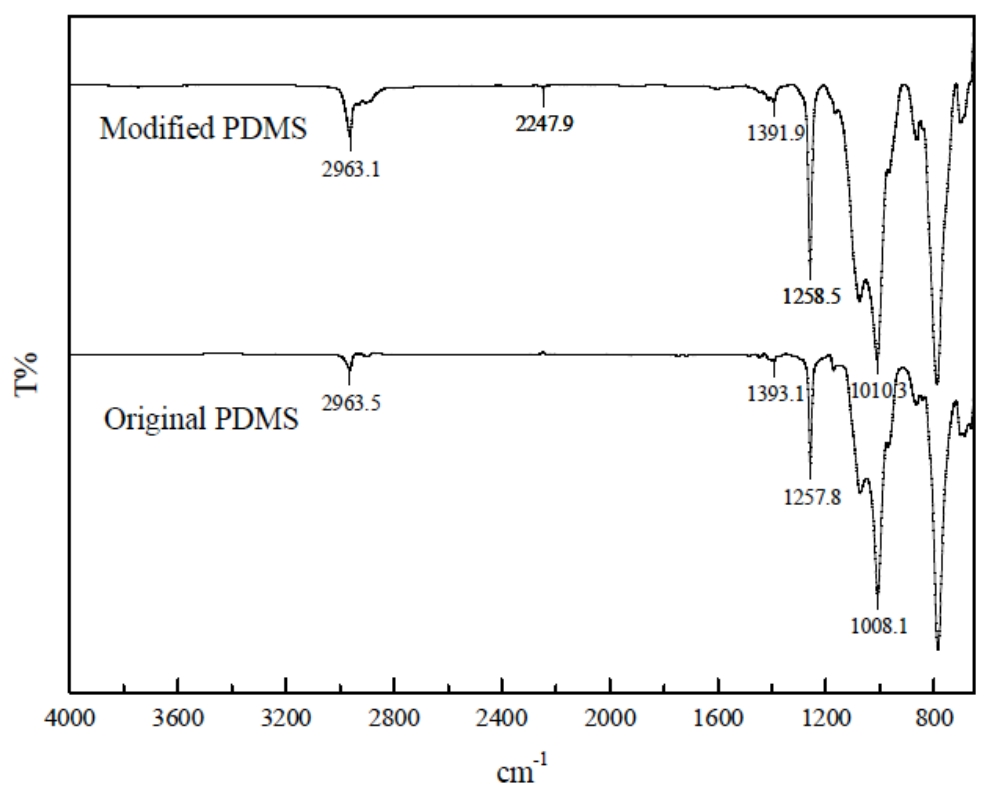

Figure 5: PDMS composite membrane infrared image.

${ }^{1}\left(\mathrm{C}-\mathrm{H}\right.$ bending vibration $\left.1490-1350 \mathrm{~cm}^{-1}\right), 1258 \mathrm{~cm}^{-1}(\mathrm{C}-$ O stretching vibration $\left.1260-1000 \mathrm{~cm}^{-1}\right), 1010 \mathrm{~cm}^{-1}$ (Si-O characteristic absorption $1100-1000 \mathrm{~cm}^{-1}$ ). It also tells that cross-linking modified membrane had an absorption peak of $2247.9 \mathrm{~cm}^{-1}$ ( $\mathrm{C} \equiv \mathrm{N}$ characteristic absorption 2260-2240 $\mathrm{cm}^{-1}$ ), which means cross-linking modification was successful to introduce $-\mathrm{CN}$ into PDMS.

Pervaporation performance in Table 2 reveals that cross-linking modification raised the phenol flux, water flux and separation factor at the same time. Crosslinking modification by using (3-cyanide propyl) triethoxy silane and the introduction of $-\mathrm{CN}$ in the membrane material would reduce the tightness of membrane, and increase the water flux. Introduction of -CN may enhance membrane materials selectivity for phenol and significantly increase the flux of phenol, so phenol flux improvement was more remarkable than water flux improvement, and so as to increase the separation factor from 4.496 to 5.793 and improve pervaporation performance, more suitable for the treatment and recycle of phenolic wastewater.

\subsection{Effect of Concentration of Cross-Linking Agent on PDMS Composite Membrane Pervaporation Performance}

To study the effect of concentration of cross-linking agent on PDMS composite membrane pervaporation performance, preparation conditions of four kinds of membrane were given in Table $\mathbf{3}$, and the pervaporation performance of membranes were given in Figure 6.

The Figure 6 showed that the separation factor presented a trend of decrease after the first increase with increase of the concentration of cross-linking agent. When the concentration of cross-linking agent was in low proportion (mass ratio 20:2:1), increase of cross-linking agent dosage made water flux decrease, phenol flux increase, and separate factor rise. Because the cross-linking agent could improve the tightness of membrane and enhanced phenol selectivity, when the mass ratio was 20:3:1, phenol flux and separate factor reached the peak, $17.52 \mathrm{~g} /\left(\mathrm{m}^{2} \cdot \mathrm{h}\right)$ and 5.793, respectively. Then continuous addition of cross-linking agent make membranes more dense, water flux

Table 3: PDMS Composite Membrane Preparation Conditions

\begin{tabular}{|c|c|c|c|}
\hline $\begin{array}{c}\text { Membrane } \\
\text { number }\end{array}$ & $\begin{array}{c}\text { Mass ratio } \\
\text { (PDMS:Cross-linking agent:DBTL) }\end{array}$ & $\begin{array}{c}\text { PDMS } \\
\text { Concentration }\end{array}$ & $\begin{array}{c}\text { Coating time } \\
\text { (min) }\end{array}$ \\
\hline \hline M1 & $20: 2: 1$ & $20 w t \%$ & 20 \\
\hline M2 & $20: 3: 1$ & $20 w t \%$ & 20 \\
\hline M3 & $20: 4: 1$ & $20 w t \%$ & 20 \\
\hline M4 & $20: 5: 1$ & $20 w t \%$ & 20 \\
\hline
\end{tabular}




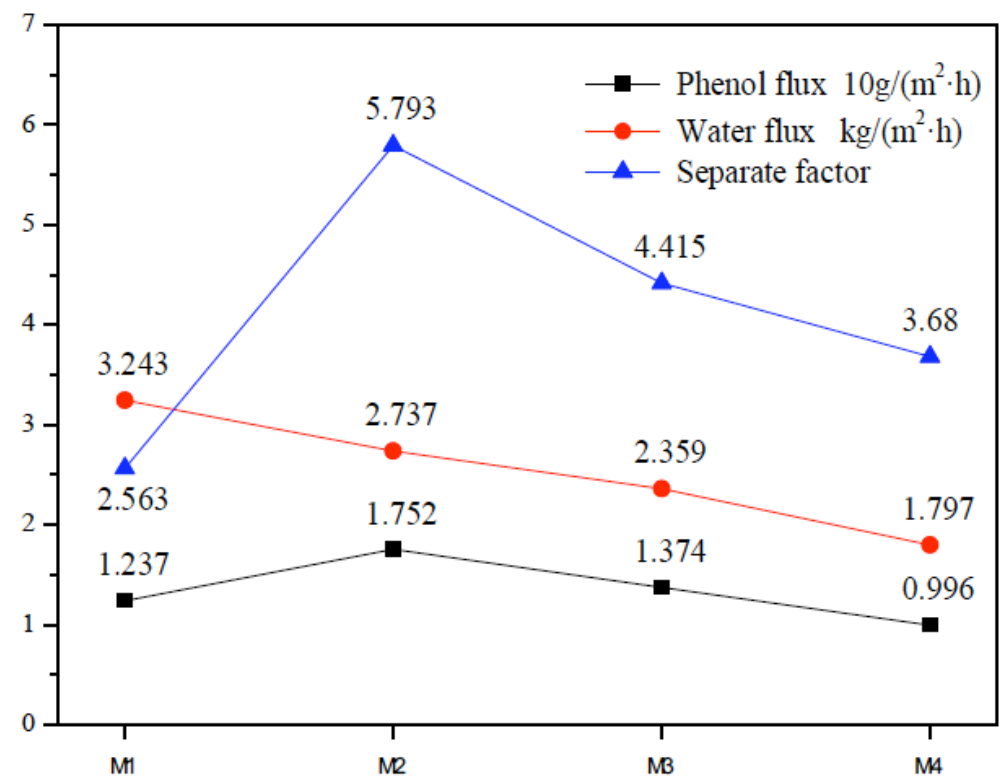

Figure 6: Effect of concentration of cross-linking agent on PDMS composite membrane pervaporation performance.

continues to decline. The resistance of phenol molecules through membrane increased, the phenol flux decreased, and the separation factor presented downward trend.

\subsection{Effect of Concentration of PDMS on PDMS Composite Membrane Pervaporation Performance}

To study the effect of concentration of PDMS on PDMS composite membrane pervaporation performance, preparation conditions of four kinds of membrane were given in Table $\mathbf{4}$ and the pervaporation performance of membranes were given in Figure 7.

The Figure 7 showed that with the increase of PDMS concentration, phenol flux and water flux were both decreased, whereas the separation factor presented a trend of decrease after the first increase. Because PDMS concentration would determine casting solution viscosity, so the greater the concentration, the higher the viscosity. When PDMS concentration was too low, the viscosity was low, the formation of separate layer was thin, and resistance of phenol and water through membrane was low which made the separation factor low. At the same time, if the PDMS concentration was too high, viscosity was high which made separation layer dense, resistance of phenol and water through membrane was high, so phenol flux and water flux were at low levels, and the separation factor was low. In addition high viscosity was not conducive to dynamic coating process; high viscosity solution was easy to make the hollow fiber membrane obstruction and internal coating uneven. Therefore, appropriate PDMS concentration was very important for high quality coating.

\subsection{Effect of Coating Time on PDMS Composite Membrane Pervaporation Performance}

Preparation conditions of four kinds of membrane were given in Table $\mathbf{5}$ and the pervaporation performance of membranes were given in Figure 8.

The Figure 8 showed that with the increase of PDMS concentration, phenol flux and water flux were both decreased, whereas the separation factor presented a trend of decrease after the first increase. Coating time extended from $20 \mathrm{~min}$ to $40 \mathrm{~min}$, water flux

Table 4: PDMS Composite Membrane Preparation Conditions

\begin{tabular}{|c|c|c|c|}
\hline $\begin{array}{c}\text { Membrane } \\
\text { number }\end{array}$ & $\begin{array}{c}\text { Mass ratio } \\
\text { (PDMS:Cross-linking agent:DBTL) }\end{array}$ & $\begin{array}{c}\text { PDMS } \\
\text { Concentration }\end{array}$ & $\begin{array}{c}\text { Coating time } \\
\text { (min) }\end{array}$ \\
\hline \hline M1 & $20: 3: 1$ & $15 w t \%$ & 20 \\
\hline M2 & $20: 3: 1$ & $20 w t \%$ & 20 \\
\hline M3 & $20: 3: 1$ & $25 w t \%$ & 20 \\
\hline M4 & $20: 3: 1$ & $30 w t \%$ & 20 \\
\hline
\end{tabular}




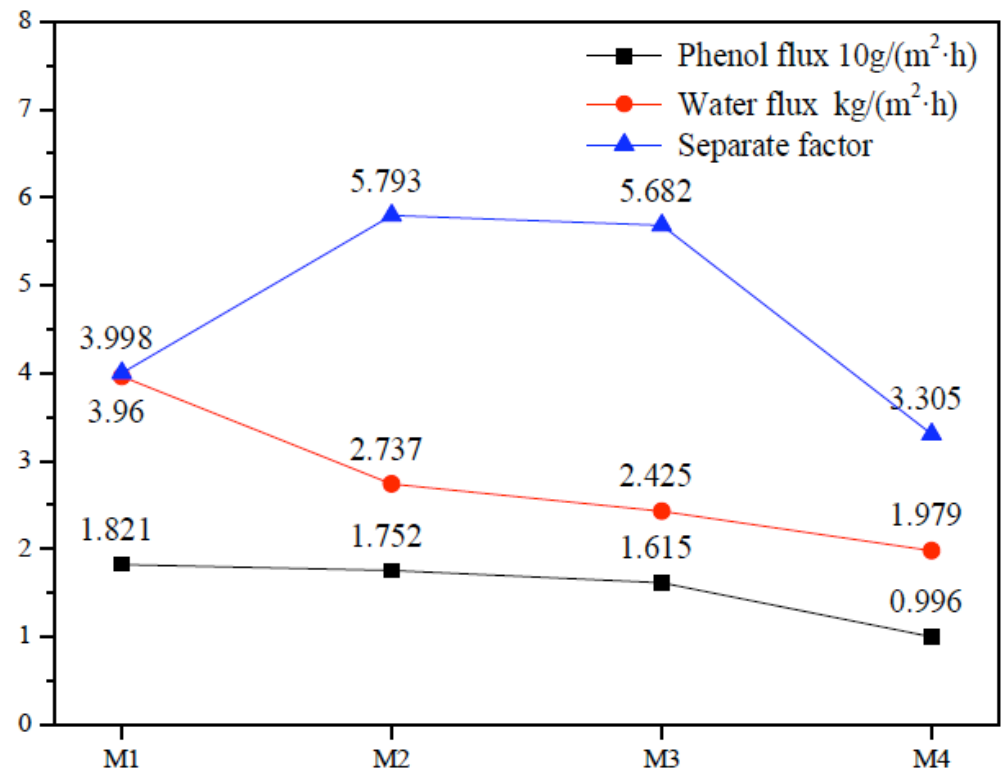

Figure 7: Effect of concentration of PDMS on PDMS composite membrane pervaporation performance.

Table 5: PDMS Composite Membrane Preparation Conditions

\begin{tabular}{|c|c|c|c|}
\hline $\begin{array}{c}\text { Membrane } \\
\text { number }\end{array}$ & $\begin{array}{c}\text { Mass ratio } \\
\text { (PDMS:Cross-linking agent:DBTL) }\end{array}$ & $\begin{array}{c}\text { PDMS Concentration } \\
\text { (min) }\end{array}$ & $\begin{array}{c}\text { Coating time } \\
20\end{array}$ \\
\hline \hline M1 & $20: 3: 1$ & $20 w t \%$ & 40 \\
\hline M2 & $20: 3: 1$ & $20 w t \%$ & 60 \\
\hline M3 & $20: 3: 1$ & $20 w t \%$ & 80 \\
\hline M4 & $20: 3: 1$ & & \\
\hline
\end{tabular}

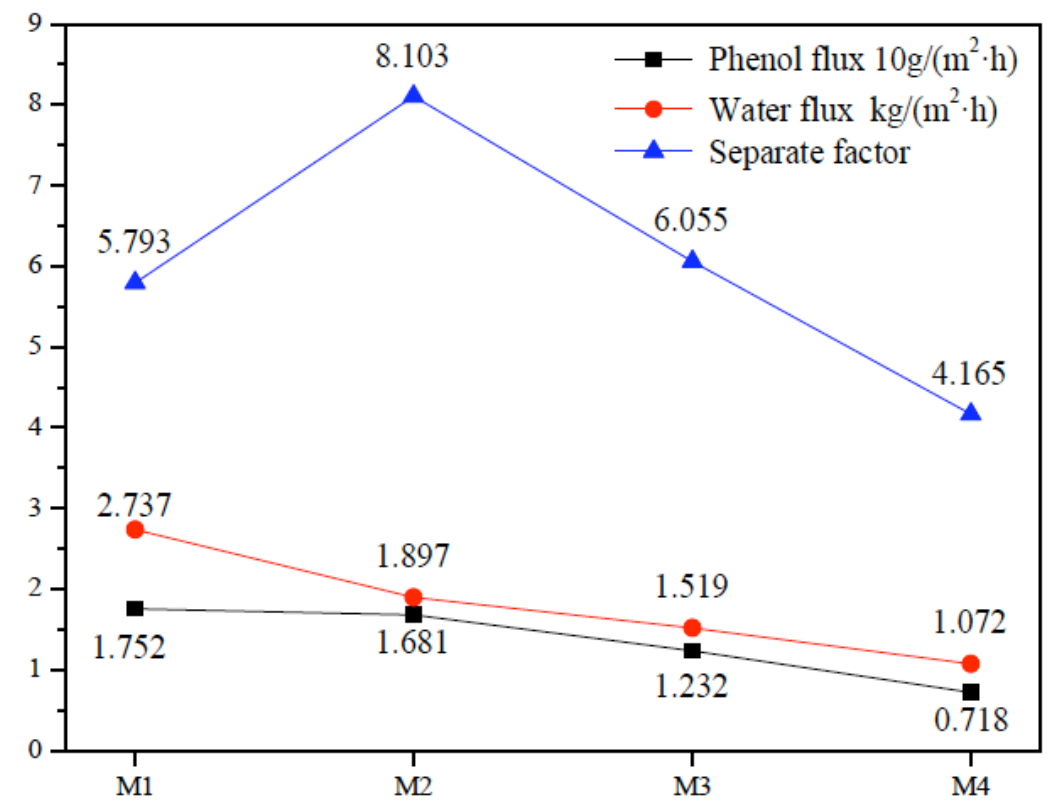

Figure 8: Effect of concentration of coating time on PDMS composite membrane pervaporation performance.

decreased significantly, phenol flux decreased from $17.52 \mathrm{~g} /\left(\mathrm{m}^{2} \cdot \mathrm{h}\right)$ to $16.81 \mathrm{~g} /\left(\mathrm{m}^{2} \cdot \mathrm{h}\right)$, separate factor increased from 5.793 to 8.103 , and membrane pervaporation performance was the best at this time. Then extended coating time, phenol flux, water flux and separate factor all decreased. Because the coating 
time determined the thickness of separate layer, long coating time would result in thicker separate layer, and furthermore greater resistant of phenol and water.

\section{CONCLUSION}

PDMS/PVDF hollow fiber pervaporation composite membrane was made by dynamic negative pressure coating method, used to treat coal gasification wastewater containing phenol. PDMS membrane materials form perfect dense endodermis on the inner surface and combine with PVDF internal structure and construct a composite structure.

PDMS material was cross-linking modified by (3cyanide propyl) triethoxy silane and the introduction of $-\mathrm{CN}$ in membrane which could enhance selectivity for phenol and separate factor, more suitable for treating phenolic wastewater.

The influence of cross-linking agent, PDMS concentration, coating time on the pervaporation performance of the composite membrane was investigated. The membrane, mass ratio as PDMS: (3cyanide propyl) triethoxy silane: $D B T L=20: 3: 1$, concentration of PDMS 20 wt \%, coated 40min, pervaporation performed the best. Actual coal chemical industry wastewater with phenol concentration 1600-
$1800 \mathrm{mg} / \mathrm{L}$, COD $13000-15000 \mathrm{mg} / \mathrm{L}$ was treated by the obtained PDMS/PVDF composite membrane, at temperature $70^{\circ} \mathrm{C}$, the flow rate of $10 \mathrm{~L} / \mathrm{h}$, pressure under membrane $3 \mathrm{KPa}$, phenol flux was 16.81 $\mathrm{g} /\left(\mathrm{m}^{2} \cdot \mathrm{h}\right)$, separation factor reached 8.103 .

\section{REFERENCE}

[1] Berardinelli S, Resini C, Arrighi L. Technologies for the removal of phenol from fluid streams: A short review of recent developments [J]. J Hazardous Mater 2008; 160(2): 265-88. http://hww.hciencedirect.com/science/article/pii/ S0304389408004172

[2] Athayde AL, Baker RW, Daniels R, et al. Pervaporation for wastewater treatment [J]. Chemtech 1997; 27(1): 34-9. http://www.osti.gov/energycitations/product.biblio.jsp?osti_ld $=438874$

[3] Zhang G, Song X, Ji S, et al. Self-assembly of inner skin hollow fiber polyelectrolyte multilayer membranes by a dynamic negative pressure layer-by-layer technique [J]. $\mathrm{J}$ Membr Sci 2008; 325(1): 109-16.

http://dx.doi.org/10.1016/J.Memsci.2008.07.016

[4] Tsai $\mathrm{H}-\mathrm{A}$, Chen $\mathrm{W}-\mathrm{H}$, Kuo $\mathrm{C}-\mathrm{Y}$, et al. Study on the pervaporation performance and long-term stability of aqueous iso-propanol solution through chitosan/polyacrylonitrile hollow fiber membrane [J]. J Membr Sci 2008; 309(1-2): 146-55. http://dx.doi.org/10.1016/J.Memsci.2007.10.018

[5] Bennett $M$, Brisdon B, England $R$, et al. Performance of pdms and organofunctionalised pdms membranes for the pervaporative recovery of organics from aqueous streams [J]. J Membr Sci 1997; 137(1): 63-88. http://dx.doi.org/10.1016/S0376-7388(97)00183-X

\section{DOI: http://dx.doi.org/10.6000/1929-6037.2013.02.03.1}

(C) 2013 Jie et al.; Licensee Lifescience Global.

This is an open access article licensed under the terms of the Creative Commons Attribution Non-Commercial License (http://creativecommons.org/licenses/by-nc/3.0/) which permits unrestricted, non-commercial use, distribution and reproduction in any medium, provided the work is properly cited. 